\title{
TEKNIK PENGOPERASIAN ALAT TANGKAP ROMPONG (SURROUNDING NET) DI SUNGAI KAPUAS, KALIMANTAN BARAT
}

\author{
Sidarta Gautama1) \\ 1)Teknisi Litkayasa pada Balai Riset Perikanan Perairan Umum, Mariana-Palembang \\ Teregristasi I tanggal: 1 Juni 2006; Diterima setelah perbaikan tanggal: 10 Juni 2006; Disetujui terbit tanggal: 27 Maret 2007
}

\section{PENDAHULUAN}

Sungai Kapuas dengan panjang $1.086 \mathrm{~km}$ (Bappeda Kalimantan Barat, 2002) dan ditambah dengan anak sungai merupakan sumber daya alam penting di Propinsi Kalimantan Barat. Pada bagian hilir Sungai Kapuas (down stream) yang melewati kabupaten dan Kota Pontianak, merupakan perairan yang dipengaruhi oleh pasang surut air laut atau perairan estuari (Samuel et al., 2004). Kegiatan penangkapan di daerah aliran Sungai Kapuas boleh dikatakan terjadi sepanjang tahun, dengan tingkat intensitas, jumlah dan keragaman alat tangkap yang bervariasi yang disesuaikan dengan lokasi dan musim. Menurut Samuel et al. (2005) telah ditemukan 9 jenis alat tangkap yang dioperasikan di daerah aliran Sungai Kapuas. Satu di antara rompong (Surrounding net).

Rompong hanya dioperasikan pada bagian hilir Sungai Kapuas (dekat muara) khusus di Sungai Kakap (anak Sungai Kapuas), sekitar Desa Sungai Kakap Kecamatan Kakap, Kabupaten Pontianak (Lampiran Gambar 1). Pengoperasian alat ini memanfaatkan fluktuasi air pasang surut. Alat ini berfungsi sebagai rumpon di mana jenis ikan termasuk udang tertarik untuk berlindung atau berkumpul di tempat yang ada balok kayu yang telah dipasang.

Informasi mengenai teknik pengoperasian, deskripsi alat, lokasi penangkapan, dan hasil tangkapan terbatas, untuk itu dilakukan pengamatan penggunaan alat tangkap tersebut. Pengamatan pengoperasian alat tangkap ini merupakan bagian dari kegiatan riset aktivitas penangkapan dan distribusi udang galah (Macobrachium rosenbergii) di daerah aliran Sungai Kapuas, Kalimantan Barat tahun 2005.

\section{DESKRIPSI ALAT TANGKAP}

1. Alat tangkap rompong adalah sekumpulan kayu (jenis kayu rambai atau tenggelam bila di air) yang berfungsi sebagai rumpon, di mana jenis ikan termasuk udang tertarik untuk berlindung atau berkumpul.

2. Untuk menahan kayu agar tidak keluar dari lahan penangkapan, dipasang beberapa tonggak (10 sampai dengan 16 batang) kayu atau bambu panjang $\pm 2 \mathrm{~m}$ yang ditancapkan di dasar perairan. Satu di antara tonggak tersebut panjang $\pm 4 \mathrm{~m}$ dan pada ujung kayu tersebut diikatkan kain kecil dibuat seperti bendera yang berfungsi sebagai tanda, sehingga pada saat air pasang terlihat untuk memudahkan penumpukan kayu dan pemasangan tonggak, dilakukan saat air surut pada kedalaman $\pm 1 \mathrm{~m}$.

3. Tumpukan kayu dibiarkan selama 7 sampai dengan 10 hari pada saat air mulai pasang, dengan ketinggian air mencapai $\pm 3 \mathrm{~m}$, sampai dengan diperkirakan tumpukan kayu tersebut berlumut.

4. Pada saat air surut $\pm 1 \mathrm{~m}$ lahan tangkapan dikurung persegi dengan menggunakan hampang, yang terbuat dari beberapa bilah bambu yang telah dijalin.

5. Proses pengoperasian alat dilakukan oleh 2 sampai dengan 3 orang.

6. Pengoperasian alat dapat dilakukan sepanjang tahun.

\section{BAHAN DAN METODE}

\section{Bahan}

Untuk 1 unit alat tangkap rompong dengan ukuran lahan $4 \times 4$ m membutuhkan:

1. 300 batang kayu dengan setiap batang berdiameter $10 \mathrm{~cm}$ panjang $100 \mathrm{~cm}$ (jenis kayu rambai) tergolong kayu kelas II, berfungsi sebagai rumpon.

2. 15 batang kayu berdiameter $\pm 5 \mathrm{~cm}$ panjang $\pm 2 \mathrm{~m}$, 1 batang kayu berdiameter $\pm 5 \mathrm{~cm}$ panjang $\pm 4 \mathrm{~m}$ (semua kayu tersebut berfungsi untuk menahan kayu agar tidak keluar dari lahan tangkapan).

3. Kain kecil dibuat berbentuk bendera sebagai tanda.

4. Hampang terbuat dari beberapa bilah bambu yang telah dijalin, panjang bentangan $\pm 20 \mathrm{~m}$ (gabungan dari beberapa unit hampang) tinggi $1,20 \mathrm{~m}$.

5. Serok, alat bantu untuk pengambilan hasil.

6. Wadah penampungan hasil.

\section{Pengoperasian Alat Tangkap}

1. Prosedur pemasangan alat tangkap:

a. Rompong dipasang pada tanah beting yaitu tanah yang agak menjorok ke arah air dan tidak begitu dalam. 
b. Pada saat air surut $\pm 1 \mathrm{~m}, 300$ batang kayu diletakkan pada lahan tangkapan yang telah ditentukan (Lampiran Gambar 2).

c. Tancapkan 16 batang kayu atau bambu sebagai tonggak dengan jarak tonggak ke tonggak $\pm 1 \mathrm{~m}$ ) dan lahan tangkapan membentuk persegi 4x4 m.

d. Ikatkan kain kecil pada salah satu tonggak sebagai tanda. Bila air pasang mencapai $\pm 3 \mathrm{~m}$ tanda tersebut terlihat (Lampiran Gambar 4).

e. Biarkan alat tangkap tersebut sampai dengan 7 hari. Bila kayu-kayu tersebut baru biarkan sampai dengan 10 hari, sampai dengan kayu-kayu tersebut diperkirakan sudah berlumut.

2. Proses pengambilan hasil tangkapan:

a. Pengambilan hasil tangkapan dilakukan pada waktu air surut $\pm 1 \mathrm{~m}$. Berdasarkan pada informasi nelayan surut terjadi pada sore atau pagi hari. Selanjutnya, lahan tangkapan dikurung dengan cepat menggunakan beberapa unit hampang, lalu diikatkan pada tonggak. Dipastikan tidak ada lagi celah untuk ikan atau udang lolos dari lahan tangkapan (Lampiran Gambar 3).

b. Dari dalam lahan tangkapan dikeluarkan kayu-kayu secara bertahap, sambil mempersempit lahan dengan cara menggeser hampang sedikit demi sedikit, serta tonggak satu persatu dicabut dan seterusnya sampai dengan kayu-kayu tersebut keluar semua, dan lahan telah menyempit $\pm 2 \mathrm{~m}^{2}$. Pada saat mengeluarkan kayu-kayu sebaiknya tidak jauh dari lahan tangkapan, karena kayu yang dikeluarkan tersebut merupakan lahan tangkapan berikut. Kemudian di tempat tersebut dilangsungkan prosedur pemasangan alat. Setiap 1 kali upaya pengambilan hasil dapat dilakukan terhadap 3 sampai dengan 7 unit rompong.

c. Gunakan serok untuk mengambil hasil dan ikan maupun udang dimasukkan pada wadah yang telah disediakan.

\section{HASIL DAN BAHASAN}

Pengamatan proses penangkapan dan pengoperasian alat dilakukan pada akhir bulan Desember 2005 di lokasi bagian hilir daerah aliran Sungai Kapuas tepat di Sungai Kakap yang merupakan salah satu anak Sungai Kapuas sekitar Desa Sungai Kakap, Kecamatan Kakap, Kabupaten Pontianak. Data diperoleh dengan melakukan wawancara langsung pada nelayan yaitu Bapak Ahmad atau Awit yang mempunyai 75 unit alat tangkap rompong dan sudah mendapat izin lokasi dari Dinas Kelautan dan Perikanan, Pontianak (Lampiran Gambar 5).

Pengamatan dilakukan terhadap 4 unit rompong yang dioperasikan selama 7 hari. Hasil tangkapan didominasi oleh udang galah (Macobrachium rosenbergii) yaitu $67,4 \%$ diikuti oleh ikan sembilang (Paraplotosus albilabris) 13,04\%, tilan (Mastacembelus sp.) 6,52\%, baung sungai (Mystus sp.) 4,35\%, kengon 4,35\%, betutu (Oxyeleotris sp.) $2,17 \%$, dan pasir-pasir (Nemacheilus fasciatus) $2,17 \%$ (Tabel 1). Satu kali pengambilan hasil total tangkapan adalah $4.600 \mathrm{~g}$ per 4 alat per upaya atau rata-rata $1.150 \mathrm{~g}$ per alat per upaya (Tabel 2).

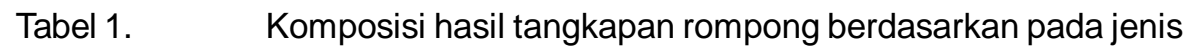

\begin{tabular}{clcc}
\hline No. & Jenis tangkapan & $\begin{array}{c}\text { Hasil tangkapan } \\
\text { Kg per 17 alat per upaya }\end{array}$ & $\begin{array}{c}\text { Bobot } \\
\text { (\%) }\end{array}$ \\
\hline 1. & Udang galah (Macobrachium rosenbergii) & 3,1 & 67,40 \\
2. & Sembilang (Parapotosus abbilabris) & 0,6 & 13,04 \\
3. & Tilan (Mastacembelus sp.) & 0,3 & 6,52 \\
4. & Baung sungai (Mystus sp.) & 0,2 & 4,35 \\
5. & Kengon & 0,2 & 4,35 \\
6. & Betutu (Oxyeleotris sp.) & 0,1 & 2,17 \\
7. & Pasir-pasir (Nemacheilus fasciatus) & 0,1 & 2,17 \\
\hline & Jumlah & $\mathbf{4 , 6}$ & $\mathbf{1 0 0}$ \\
\hline
\end{tabular}

Tabel 2. Hasil tangkapan rompong rata-rata g per alat per upaya

\begin{tabular}{|c|c|c|c|}
\hline No. & Jenis tangkapan & $\begin{array}{c}\text { Hasil tangkapan } \\
\text { g per } 17 \text { alat per upaya }\end{array}$ & $\begin{array}{c}\text { Rata-rata } \\
\text { g per alat per upaya }\end{array}$ \\
\hline 1. & Udang galah (Macobrachium rosenbergin) & 3.100 & 775 \\
\hline 2. & Sembilang (Parapbotosus abilibris) & 600 & 150 \\
\hline 3. & Tilan (Mastacembeus sp.) & 300 & 75 \\
\hline 4. & Baung sungai (Mystus sp.) & 200 & 50 \\
\hline 5. & Kengon & 200 & 50 \\
\hline 6. & Betutu (Oxyeleotris sp) & 100 & 25 \\
\hline 7. & Pasir-pasir (Nemacheilus fasciatus) & 100 & 25 \\
\hline \multicolumn{2}{|r|}{ Jumlah } & 4.600 & 1.150 \\
\hline
\end{tabular}




\section{KESIMPULAN}

1. Alat tangkap rompong (surrounding net) yang berfungsi sebagai rumpon, berfungsi untuk mengumpulkan ikan atau udang.

2. Pengoperasian rompong memanfaatkan fluktuasi air pasang surut, dipasang pada tanah beting yaitu tanah yang agak menjorok ke arah air dan tidak begitu dalam. Pengoperasian alat dan pengambilan hasil tangkapan dilakukan oleh 2 sampai dengan 3 orang.

3. Hasil tangkapan didominasi oleh udang galah (Macobrachium rosenbergii) yaitu $67,4 \%$ diikuti oleh ikan sembilang (Paraplotosus albilabris) 13,04\%, tilan (Mastacembelus sp.) 6,52\%, baung sungai (Mystus sp.) 4,35\%, kengon 4,35\%, betutu (Oxyeleotris sp.) 2,17\%, dan pasir-pasir (Nemacheilus fasciatus) 2,17\%.

\section{DAFTAR PUSTAKA}

Bappeda-Kalimantan Barat. 2002. Pemetaan liputan Iahan Propinsi Kalimantan Barat. Laporan akhir
Pusat Survei SDA. Bakosurtanal dengan Badan Pemerintah Daerah Kalimantan Barat. 63 hal.

Samuel, S. Nurdawati, S. Gautama, \& Makri. 2004. Pengaruh ikan budi daya terlepas dalam komposisi hasil tangkapan populasi ikan asli di Sungai Kapuas, Kalimantan Barat. Laporan Teknis Balai Riset Perikanan Perairan Umum. Palembang. 53 hal.

Samuel, S. N. Aida, A. I. J. Asaad, S. Gautama, \& Marson. 2005. Aktivitas penangkapan dan distribusi udang galah (Macobrachium rosenbergii) di daerah aliran Sungai Kapuas, Kalimantan Barat. 55 hal.

\section{UCAPAN TERIMA KASIH}

Penulis menyampaikan terima kasih yang sebesar-besarnya pada Bapak Ir. Samuel yang telah memberikan masukan dan koreksi, juga pada tim penilai dan penerbit sehingga dapat terlaksana tulisan ini. 
Lampiran1. Lokasi pengoperasian alat tangkap rompong

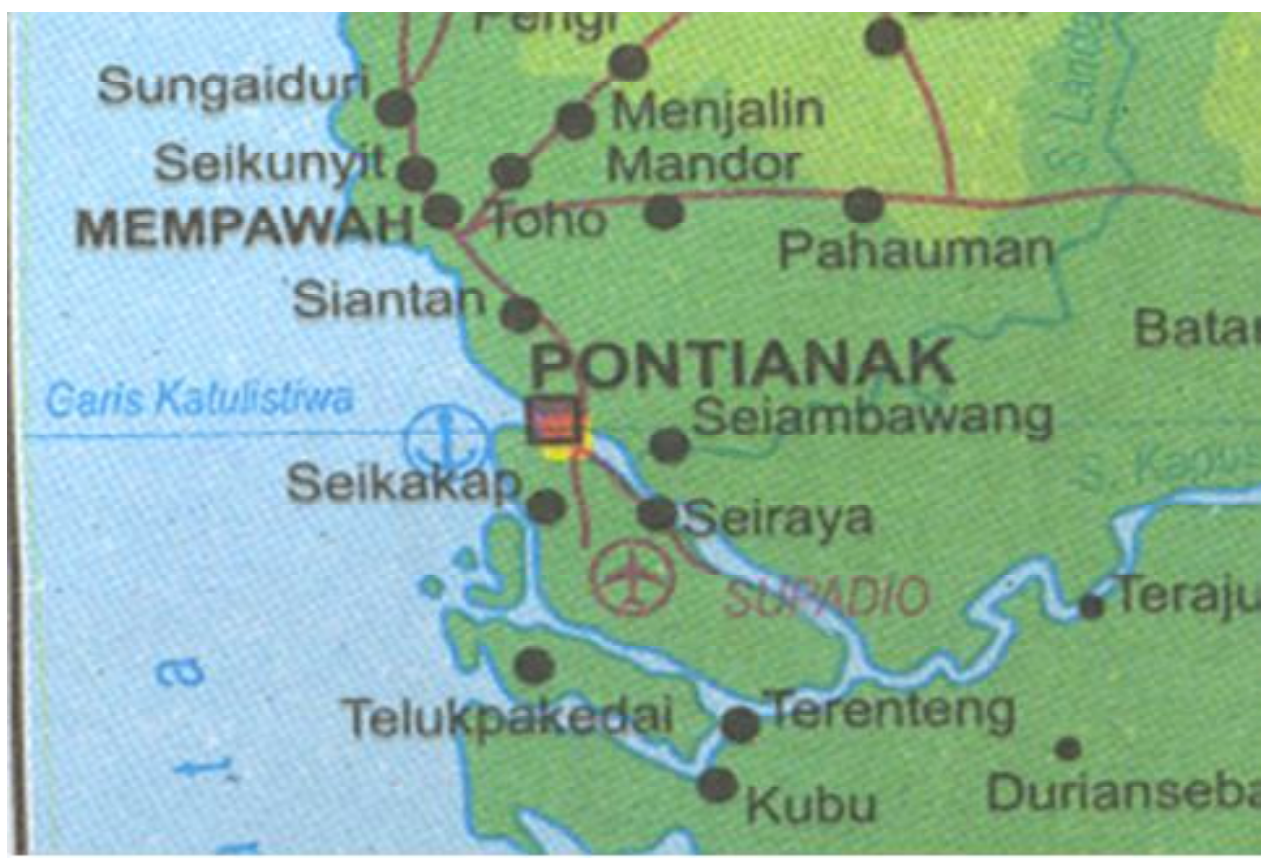

Lampiran 2. Alat tangkap rompong (tampak atas)

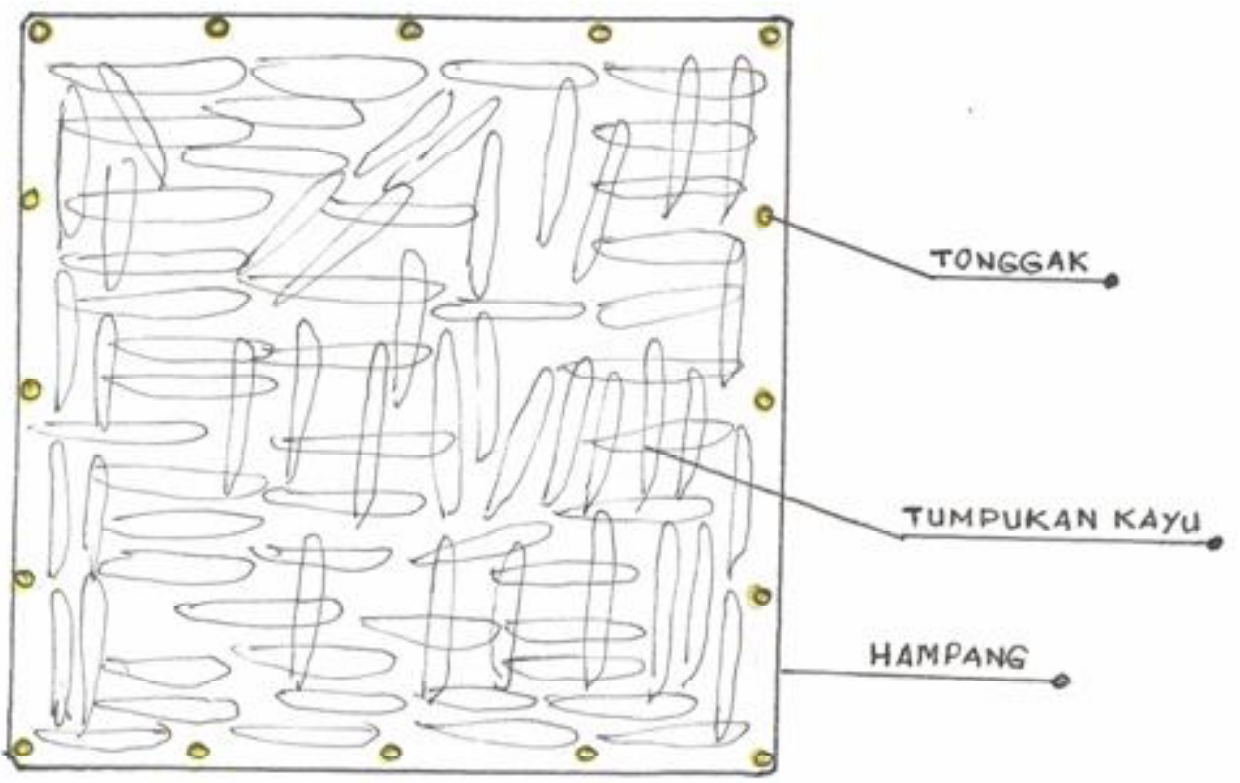


Lampiran 3. Alat tangkap rompong, siap dilakukan pengambilan hasil

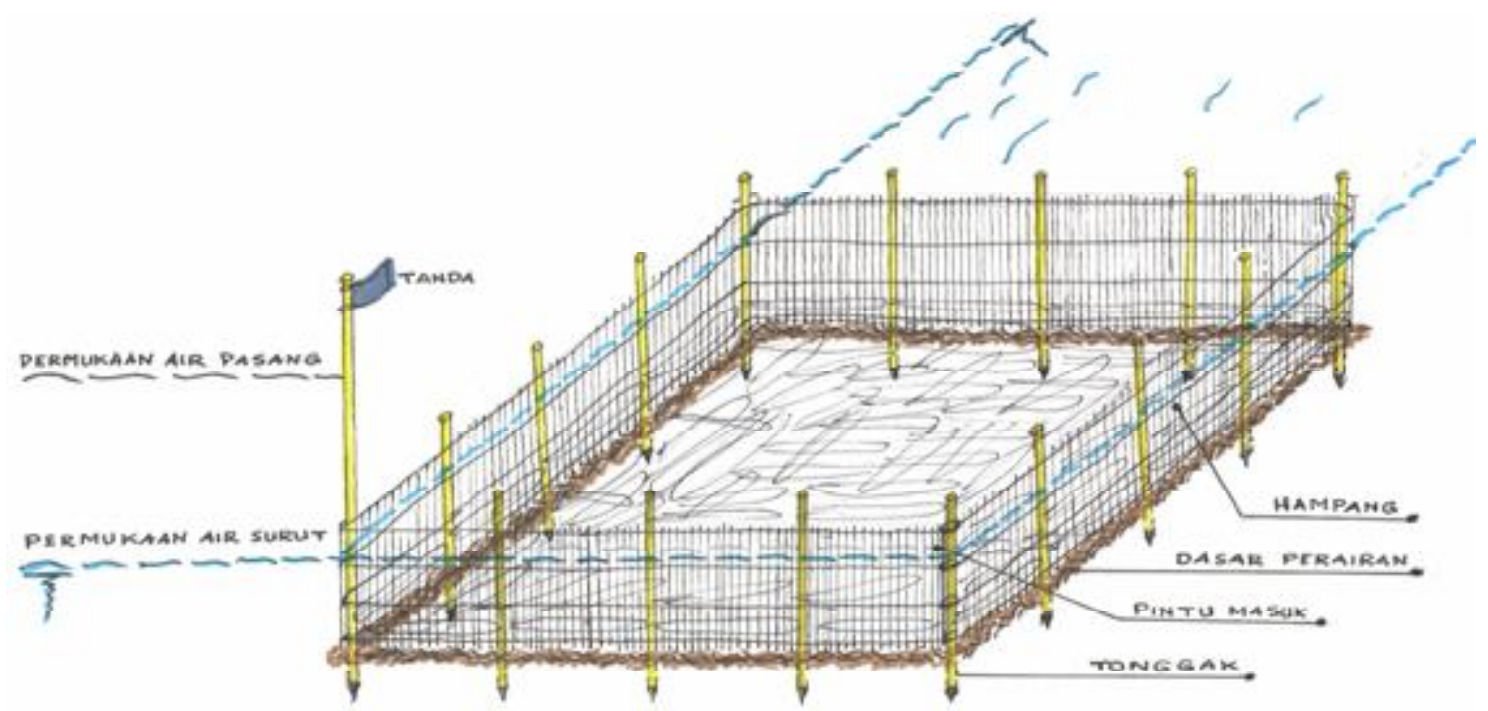

Lampiran 4. Tanda yang merupakan sederetan alat tangkap rompong di saat air pasang

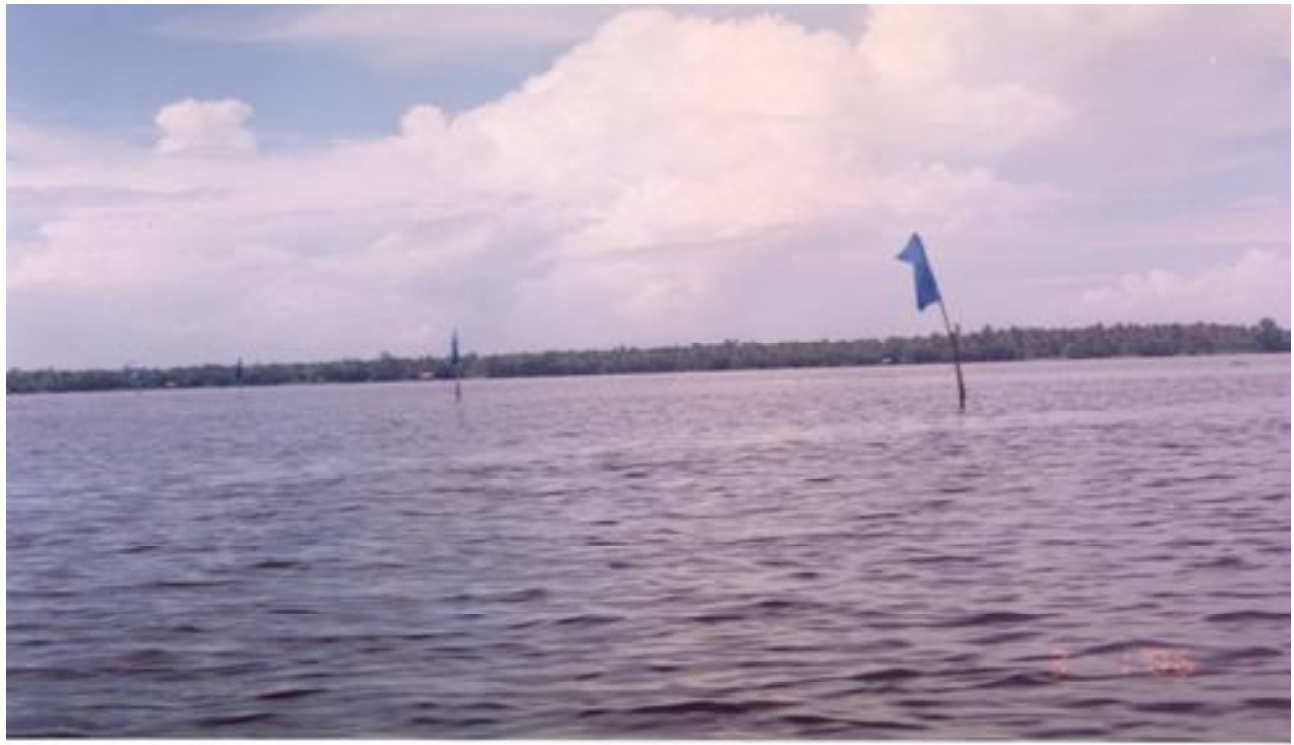


Lampiran 5. Denah lokasi alat tangkap rompong yang dikuasai oleh nelayan Bapak Ahmat atau Awit

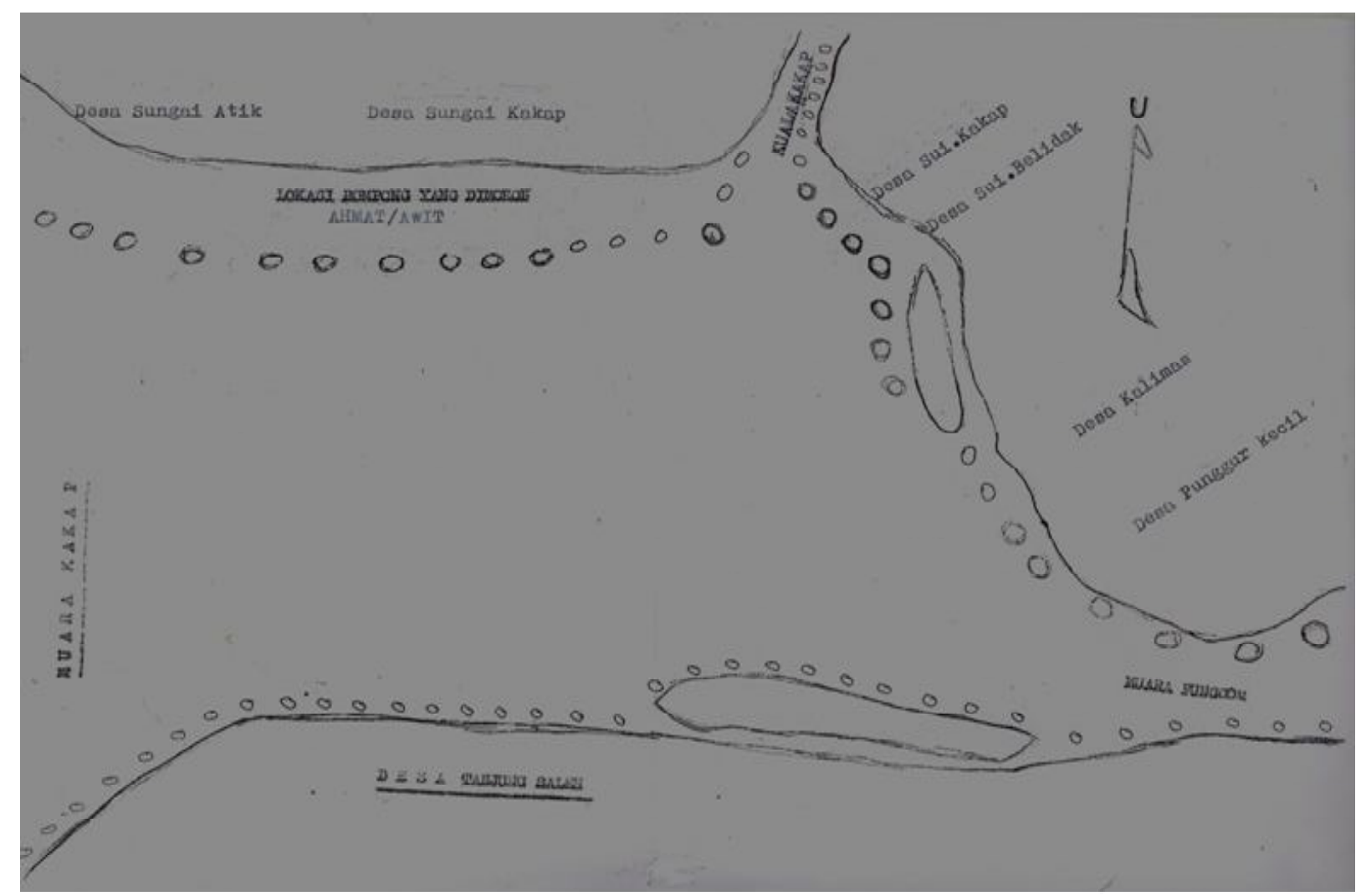

